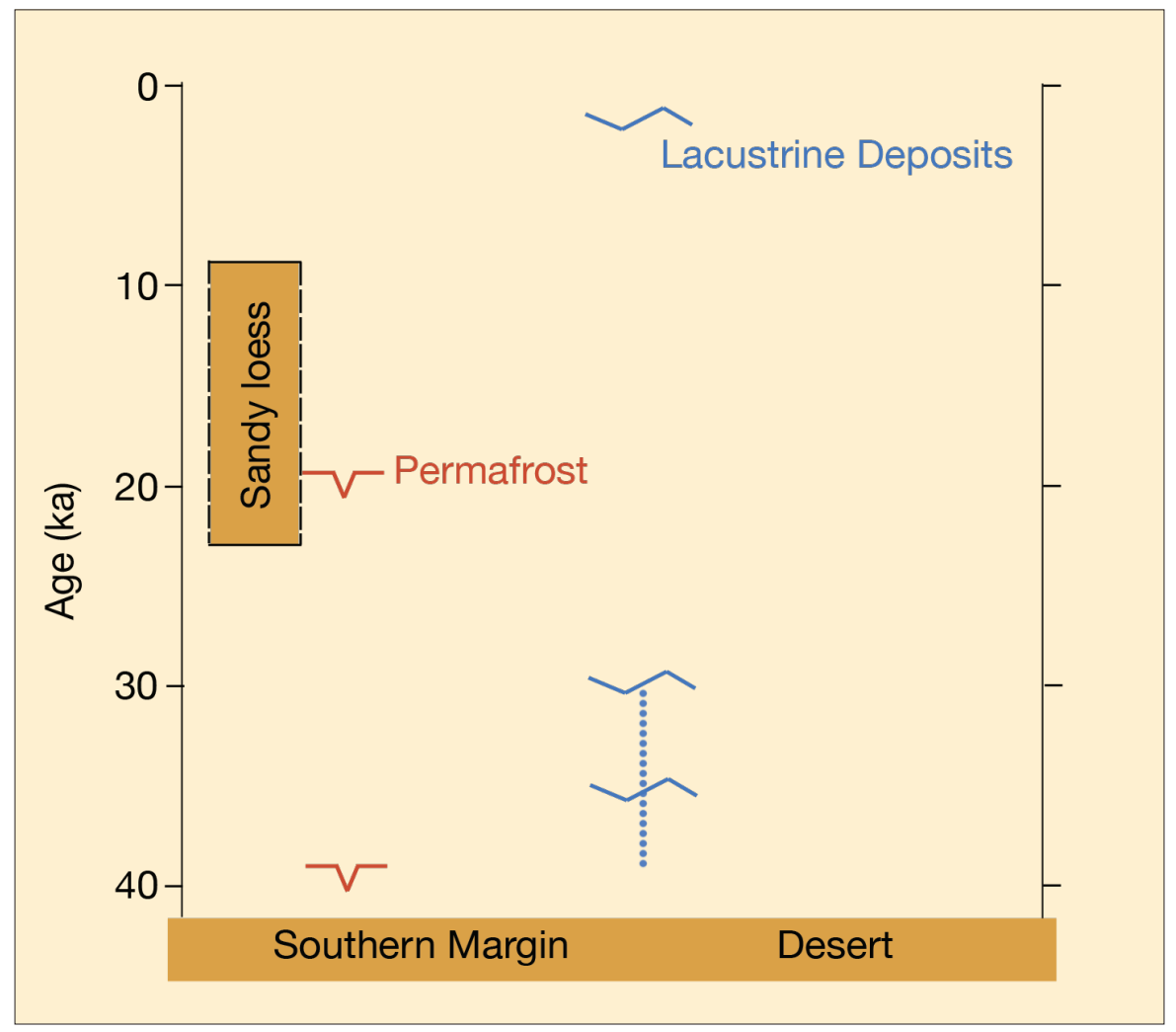

Figure 2: Wetter climate in the Taklamakan Desert of China (recognized from lacustrine processes) and colder times on its south margin (recognized from permafrost processes) (modified from Yang et al., 2006).

throughout the glacials and interglacials of the late Quaternary, with no large-scale hiatus recorded. In contrast, geomorphological and sedimentological records from the Atacama Desert, southern Peru show several phases of drier conditions during the Holocene. Further, sedimentological evidence for the three periods of lake formation during the last $40 \mathrm{kyr}$ in the hyperarid center of the Taklamakan Desert, western China was discussed (Fig. 2). The obvious inconsistencies of paleoclimatic histories between different deserts reconfirm the need for detailed regional desert studies in order to comprehensively understand of paleoclimatic changes in the arid regions of the world.

The workshop also attracted a great deal of attention from the Government of Alashan District, demonstrating the importance of paleoenvironmental studies to society. The local appreciation was shown not only by a welcoming address from a Governor but also by an excellent banquet-with superb Mongolian singing and dancing, and many friendly toastsprovided by the government of the district.

Publications of workshop presentations are currently in preparation. Papers on land degradation and desertification are being considered for a special issue in Geographical Research (March 2009 issue; vol. 47 no. 1), and manuscripts on geomorphology and paleoenvironmental changes for publication in Quaternary Research.

\section{Reference}

Yang, X., Preusser, F. and Radtke, U., 2006: Late Quaternary environmental changes in the Taklamakan Desert, western China, inferred from OSL-dated lacustrine and aeolian deposits, Quaternary Science Reviews, 25: 923-932.

\title{
First Asian dendrochronology conference and workshop: Environmental change and human activity
}

\section{Bangkok, Thailand, 9-15 September 2007}

\author{
Nathsuda Pumijumnong \\ Faculty of Environment and Resource Studies, Mahidol University, Thailand; gmpm@mahidol.ac.th
}

The First Asian Dendrochronlogy Conference and Workshop "Environmental Change and Human Activity" was held in Bangkok, Thailand, in conjunction with a seminar organized by Won-kyu Park, South Korea and Liu Yu, China, and a special one-day course on "Wood anatomy in dendrochronology: concepts, methods, image analysis system and SEM" by Kambiz Pourtahmasi, Iran. The conference allowed researchers in dendrochronology and other disciplines related to climate dynamics and forest science to present their most recent research achievements. It also offered a platform for students and young scientists to present their projects, organize collaborations and arrange tree ring networks in Asia.

The conference and workshop attracted over 80 participants from twenty countries. The first day was focused on opening activities, keynotes and plenary presentations. Three keynote papers were related to issues of climate change, environmental change and human activity in Thailand. The presentations dealt with tree ring research in Thailand, climate data sets and watershed management, and climate change. The keynote session was followed by plenary presentations from several scientists. The first day was wrapped up with a session of 7 oral presentations.

The following days covered a range of topics, such as dendrochronological studies from Himalaya to East Asia, tropical dendrochronology, heavy metal contamination of plants and soil, wood anatomy, forestry and sub-fossil wood in Southeast Asia. For the third day a field trip to Putey National Park, was organized. This is a key study site for pine dendrochronology, particularly in understanding pine forest growth in monsoon climate and external disturbances on growth.

In Thailand, teak tree ring indices have been used for climate reconstruction back to 1640 AD. N. Pumijumnong presented an extended teak chronology from Thailand, which suggests several changes in temperature and precipitation between 1590 and the present. However in general, the climate in Thailand has not changed significantly over the last 300 years. According to the teak index, the climate in Thailand was relatively cool between 1590-1640 and 1800-1890. Furthermore, the precipitation in May-July (beginning of rainy season) has decreased by $0.69 \mathrm{~mm}$, and the temperature in February, March 


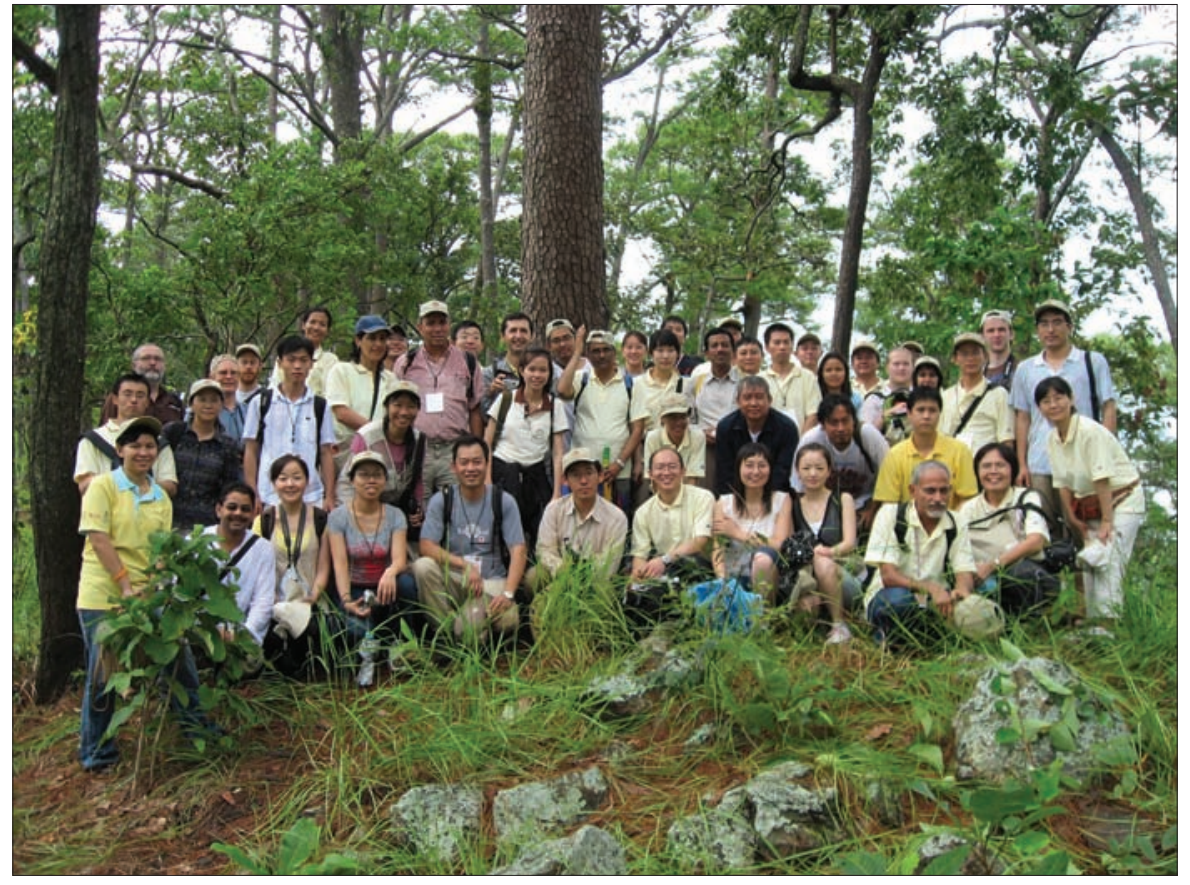

Figure 1: Workshop participants enjoying Putey National Park.

and April (hot season) has increased by $0.05-0.1^{\circ} \mathrm{C}$.

Several groups in tropical regions of south and Southeast Asia have been working to establish a good quality tree ring data network to understand monsoon variability and related global parameters (e.g., ENSO) in the recent past. In this context, teak from Indonesia, Thailand, Myanmar and India have been demonstrated as a potential source for high-resolution reconstruction of monsoon related parameters, such as rainfall, and drought frequencies and intensities.

\section{The way forward}

The Asian Dendrochronology Association (ADA) held a panel meeting to discuss future research and the way forward. The following administrative decisions were made:

- Nathsuda Pumijumnong (Thailand) was elected the new ADA president, R.R. Yadav (India) the new treasurer, Osamu Kobayashi (Japan) the new secretary, and a total of 10 representatives from each country in Asia as members. The ADA constitution's term is two years.

Membership fee for ADA is US\$10 per year ( $\$ 5$ for students). There are currently 41 members.

ADA will establish a website to be launched in December 2007. This website will be available for consultation, linkages and networking among ADA members and research institutions.

ADA will issue a newsletter three times a year.

ADA will organize a conference and workshop every two years.

- The next ADA conference will take place in Lucknow, India in 2009.

\section{New on the PAGES bookshelf}

\section{Ocean Circulation: Mechanisms and Impacts}

A publication of the American Geophysical Union

Editors: A. Schmittner, J. Chiang and S. Hemmings

This book covers all aspects of the ocean's large-scale meridional overturning circulation, and is a coherent presentation, from a mechanistic point of view, of our current understanding of paleo, present-day, and future variability and change. It presents the current state of the science by bringing together the world's leading experts in physical, chemical, and biological oceanography, marine geology, geochemistry, paleoceanography, and climate modeling.

Preface: A. Schmittner, J. Chiang and S. Hemming

Section 1. Introduction - The Ocean's Meridional Overturning Circulation Section 2. Theory and Perspectives

Section 3. Current State and Trend

Section 4. Decadal to Centennial Variability

Section 5. Past States and Millennial Variability

Section 6. Impact on Climate, Ecosystems, and Biogeochemical Cycles Section 7. Future Projections

Ordering Information:

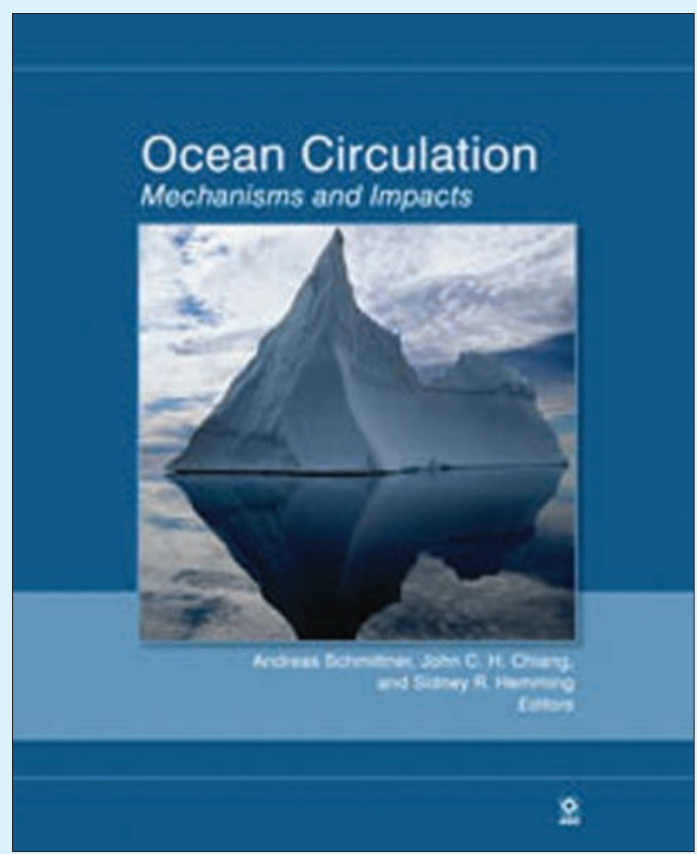

